\title{
NMDA receptors play important roles in acquisition and expression of the eyeblink conditioned response in glutamate receptor subunit $\delta 2$ mutant mice
}

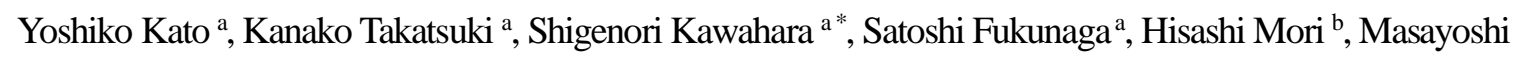
Mishina ${ }^{\mathrm{b}}$, and Yutaka Kirino ${ }^{\mathrm{a}}$

${ }^{a}$ Laboratory of Neurobiophysics, School of Pharmaceutical Sciences, The University of Tokyo, and Core Research for Evolution Science and Technology, Japan Science and Technology Agency, Tokyo 113-0033, Japan

${ }^{\mathrm{b}}$ Department of Molecular Neurobiology and Pharmacology, Graduate School of Medicine, The University of Tokyo, and Solution Oriented Research for Science and Technology, Japan Science and Technology Agency, Tokyo 113-0033, Japan

* Corresponding author. Tel.: +81-3-5841-4801; fax: +81-3-5841-4805.

E-mail address: kawahara@mol.f.u-tokyo.ac.jp (S. Kawahara). 
Abbreviations: APV, 2-amino-5-phosphonovaleric acid; CR, conditioned response; CS, conditioned stimulus; EMG, electromyogram; GluR 2 2, glutamate receptor subunit 82 ; LTD, long-term depression; NMDA, $N$-methyl-D-aspartate; US, unconditioned stimulus 


\begin{abstract}
Classical eyeblink conditioning has been known to depend critically on the cerebellum. Apparently consistent with this, glutamate receptor subunit $\delta 2$ null mutant mice (GluR $\delta 2^{--}$mice), which have serious morphological and functional deficiencies in the cerebellar cortex, are severely impaired in delay paradigm. However, these mutant mice successfully learn in trace paradigm, even in '0-trace paradigm', in which the unconditioned stimulus (US) starts just after the conditioned stimulus (CS) terminates. Our previous studies revealed that the hippocampus and the muscarinic acetylcholine receptors play crucial roles in 0 -trace paradigm in GluR $\delta 2^{--}$ mice unlike in wild-type mice, suggesting a large contribution of the forebrain to 0-trace conditioning in this type of mutant mice. In the present study, we investigated the role of $N$-methyl-D-aspartate (NMDA) receptors in 0-trace eyeblink conditioning in GluR $\delta 2^{--}$mice. Mice were injected intraperitoneally with the noncompetitive NMDA receptor antagonist (+)MK-801 (0.1 mg/kg) or saline, and conditioned with 350-ms tone CS followed by 100-ms periorbital shock US. GluR $\delta 2^{--}$mice that received (+)MK-801 injection exhibited a severe impairment in acquisition of the conditioned response (CR), compared to the saline-injected GluR $\delta 2^{-1-}$ mice. In contrast, wild-type mice were not impaired with 0-trace CR acquisition by (+)MK-801 injection. After the injection solution was changed from (+)MK-801 to saline, GluR $\delta 2^{--}$mice showed a rapid and partial recovery of CR performance. On the other hand, when the injection solution was changed from saline to (+)MK-801, GluR $\delta 2^{--}$mice showed a marked impairment in expression of the pre-acquired CR, whereas impairment of CR expression was small in wild-type mice. Injection of (+)MK-801 had no significant effects on spontaneous eyeblink frequency or startle eyeblink frequency to the tone CS in either GluR $\delta 2^{- \text {- }}$ mice or wild-type mice. These results suggest that NMDA receptors play critical roles both in acquisition and expression of the CR in 0-trace eyeblink conditioning in GluR $\delta 2^{--}$mice.
\end{abstract}

Key words: Classical conditioning, Learning, Hippocampus, Cerebellum, MK-801. 
Classical conditioning of the eyeblink response is a type of motor learning that depends critically on the cerebellum in rabbits (McCormick et al., 1982) and mice (Chen et al., 1996). Using a standard delay paradigm, in which the unconditioned stimulus (US) is delayed, overlaps and coterminates with the conditioned stimulus (CS), the essential neural circuit that resides in the cerebellum and brainstem has been extensively studied in rabbits. Thus this learning task has become a model system that is suitable for analysis of the neural substrates of learning and memory (Thompson et al., 1997). In addition to these essential brain regions, the forebrain including the hippocampus and the medial prefrontal cortex plays an important role in trace paradigm, in which a long trace-interval (a stimulus-free period of time) intervenes between the CS and US (Solomon et al., 1986; Kronforst-Collins and Disterhoft, 1998; McLaughlin et al., 2002; Takehara et al., 2002, 2003). Although this important basic framework for learning mechanism in classical eyeblink conditioning has been established in rabbit, mouse is becoming another important model because of its current progress in gene-manipulating techniques.

We have studied the eyeblink conditioning of mutant mice that lack glutamate receptor subunit $\delta 2$

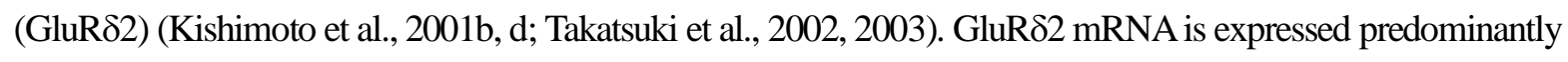
in Purkinje cells of the cerebellum whereas its expression in the forebrain is hardly detectable (Araki et al., 1993; Lomeli et al., 1993). Within Purkinje cells, GluR 22 proteins are localized exclusively at parallel fiber-Purkinje cell synapses (Takayama et al., 1996; Landsend et al., 1997). GluR82 null mutant mice (GluR $\delta 2^{--}$mice) have several morphological and functional impairments in the cerebellar cortex such as a deficit in long-term depression (LTD) at parallel fiber-Purkinje cell synapses, a fifty percent reduction in the number of these synapses, persistent multiple innervation of Purkinje cells by climbing fibers, and abnormal oscillating Purkinje cell activity (Kashiwabuchi et al., 1995; Kurihara et al., 1997; Yoshida et al., 2004). Impairments in motor coordination (Kashiwabuchi et al, 1995) and vestibular compensation (Funabiki et al., 1995) were also found in GluR $\delta 2^{--}$mice.

Apparently consistent with the hypothesis that the cerebellum and synaptic plasticity in the cerebellar cortex play a crucial role in classical eyeblink conditioning (Ito, 1989; Thompson and Krupa, 1994), GluR $\delta 2^{--}$ mice exhibited a severe impairment in a delay paradigm with a 252-ms interstimulus interval between the 352-ms CS and 100-ms US (Kishimoto et al., 2001d), as did other cerebellar LTD-deficient mice (Aiba et al., 1994; Shibuki et al., 1996; Miyata et al., 2001; Kishimoto et al., 2001a; Koekkoek et al., 2003). However, in trace paradigm with a 500-ms trace interval between the CS end and US onset, GluR $\delta 2^{--}$mice successfully acquired the eyeblink conditioned response (CR) (Kishimoto et al., 2001d). Further analysis using various temporal intervals between the CS and US revealed that GluR $\delta 2^{--}$mice learned as successfully as wild-type mice in trace paradigms with a 50-, 100-, and 250-ms trace interval, and even in the ' 0 -trace paradigm' in which the US starts just after termination of the CS (Kishimoto et al., 2001b). However, in a delay paradigm with a 352-ms interstimulus interval that is equal to that of the 0-trace paradigm with a 352-ms CS, GluR $\delta 2^{--}$mice exhibited a severe learning impairment. These results suggest that another learning mechanism, one that does not require the cerebellar LTD, underlies the ability of GluR $\delta 2^{--}$mice to learn in eyeblink conditioning paradigms in which the US does not overlap with the CS. Eyeblink conditioning in another cerebellar 
LTD-deficient mouse lacking the phospholipase C $\beta 4$ subunit also showed similar results (Kishimoto et al., 2001a).

In the course of discovering this cerebellar LTD-independent learning mechanism, we found that ablation of the hippocampus (Takatsuki et al., 2003) or blockade of muscarinic acetylcholine receptors by systemic administration of scopolamine (Takatsuki et al., 2002) severely impaired acquisition of the CR during 0 -trace conditioning in GluR $\delta 2^{--}$mice. These results suggest that the forebrain including the hippocampus contributes to the successful learning of GluR $\delta 2^{--}$mice in 0 -trace conditioning. In wild-type animals, the hippocampus has an ability to modulate acquisition during a standard delay conditioning (Salafia et al., 1979; Prokasy et al., 1983; Solomon et al., 1983) and is required in more difficult paradigms such as long-trace paradigm (Solomon et al., 1986; Moyer et al., 1990; Weiss et al., 1999; Tseng et al., 2004) and discrimination reversal paradigm (Berger and Orr, 1983). The medial prefrontal cortex also plays an important role in acquisition (Kronforst-Collins and Disterhoft, 1998; Weible et al., 2000; McLaughlin et al., 2002) and retention (Takehara et al., 2003) in long-trace conditioning paradigm. Therefore, contribution of the forebrain seems to increase when the task demand on the animal is raised. Based on this consideration, we have hypothesized that contribution of the forebrain might also increase in GluR $22^{--}$mice because the several deficiencies in the cerebellar cortex will make it difficult for the mutant mice to learn the short-trace eyeblink conditioning.

$N$-methyl-D-aspartate (NMDA) receptors are abundantly expressed in the forebrain (Watanabe et al., 1993) and many studies using NMDA receptor antagonists or gene-targeted mutant mice have revealed that NMDA receptors play important roles in several kinds of learning that depend on the forebrain. In eyeblink conditioning, Thompson and Disterhoft (1997) have demonstrated that the noncompetitive NMDA receptor antagonist (+)MK-801 slows the rate of acquisition in delay paradigm and completely blocks acquisition in 500-ms trace paradigm in rabbits. This drug is also effective in mice, in which the impairment with (+)MK-801 administration is greater in trace paradigm with a longer trace interval (Takatsuki et al. 2001). In addition, acute injections of the competitive NMDA receptor antagonist 2-amino-5-phosphonovaleric acid (APV) into the dorsal hippocampus severely impaired acquisition during 500-ms trace conditioning in mice (Sakamoto et al., 2005). Consistent with the effects of pharmacological blockade, those mutant mice that lack the NMDA receptor subunit $\varepsilon 1$ (NR2A) exhibit a mild impairment in delay paradigm and a severe impairment in long-trace paradigm (Kishimoto et al., 1997, 2001c). These results suggest that blockade of NMDA receptors greatly affects the role of the forebrain in eyeblink conditioning in mice.

In the present study, we investigated the effect of (+)MK-801 on 0-trace eyeblink conditioning in GluR $\delta 2^{--}$mice. As described above, these mutant mice critically depend on the hippocampus to learn the 0 -trace eyeblink conditioning. Therefore, blockade of NMDA receptors would result in impairment of learning as reported in long-trace eyeblink conditioning in wild-type animals. 


\section{EXPERIMENTAL PROCEDURES}

\section{Animals}

Previously-developed GluR82-mutant mice were repeatedly backcrossed with C57BL/6 mice to yield heterozygous GluR $\delta 2^{+-}$mice with a more than 99.99\% C57BL/6 genetic background (Kashiwabuchi et al., 1995; Kishimoto et al., 2001d). These heterozygous mice with highly homogeneous genetic background were crossed with each other to obtain homozygous GluR $\delta 2^{--}$mice. Both male and female mice were used and randomly assigned to saline-injected control group and (+)MK-801-injected group. No differences were detected between the results obtained from male and female mutant mice. We also investigated the effect of (+)MK-801 in wild-type C57BL/6 male mice obtained from a breeder (Japan SLC Inc., Hamamatsu, Shizuoka, Japan). These animals were kept on a 12-h light/12-h dark cycle with ad libitum access to food and water and weighed $18-27 \mathrm{~g}$ at the time of surgery. All experiments were performed in accordance with the guideline established by the Institutional Animal Investigation Committee at the University of Tokyo. All efforts were made to minimize the use of animals and to optimize their comfort.

\section{Surgery}

Surgical procedures were the same as those described previously (Takatsuki et al., 2001). Under anesthesia with ketamine (80 mg/kg, i.p.; Sankyo, Tokyo, Japan) and xylazine (20 mg/kg, i.p.; Bayer, Tokyo, Japan), four Teflon-coated stainless steel wires (No. 7910, A-M Systems Inc., Carlsborg, WA, USA) were implanted under the left eyelid. Two of these wires were used to record electromyograms (EMG) and the remaining two to deliver the US. These wires were soldered to connector pins, which were secured to the skull with dental acrylic resin and stainless steel screws. After surgery, the animals were returned to their home cages and their recovery was monitored.

\section{Drug treatments}

(+)MK-801 (0.1 mg/kg, Tocris Cookson, MO, USA) or saline was administered by intraperitoneal injection 10 min before the second adaptation session to the experimental apparatus (spontaneous recording day 2) and the subsequent daily conditioning sessions. (+)MK-801 was diluted in saline and injected in a volume of $5 \mathrm{ml} / \mathrm{kg}$ body weight. Control mice were injected with saline $(5 \mathrm{ml} / \mathrm{kg})$. The dose and the timing of injection used in the present study is sufficient to cause a severe impairment in a hippocampus-dependent long-trace eyeblink conditioning in wild-type mice as revealed in our previous study (Takatsuki et al., 2001), in which we also found higher dose $(0.2 \mathrm{mg} / \mathrm{kg}$, i.p.) reduced the startle eyeblink responses to the tone CS.

\section{Conditioning procedure}

On a day (spontaneous recording day 1) three to five days after the surgery, spontaneous eyeblink frequency was recorded for approximately 50 min without the US, CS, or drug injection. On the next day (spontaneous recording day 2), spontaneous eyeblink frequency was recorded in the same way as the day before except that (+)MK-801 or saline was injected 10 min before the start of spontaneous eyeblink recording. The eyeblink 
conditioning began the next day. A daily conditioning session consisted of 100 trials divided into 10 blocks, which had 9 CS-US paired trials followed by a CS-alone trial. Trials were separated by a variable intertrial interval, randomized between 20 and $40 \mathrm{~s}$. The CS was a 350-ms tone $(1 \mathrm{kHz}, 85 \mathrm{~dB})$ with a 5-ms rise and a 5-ms fall time. The US was a 100-ms periorbital shock (100 Hz square pulses) and was adjusted daily to elicit an eyeblink/head-turn response in each animal. We used '0-trace paradigm', in which the US starts just after the CS terminates. (+)MK-801 or saline was injected $10 \mathrm{~min}$ before the daily conditioning. All experiments were carried out during the light phase of the light/dark cycle.

\section{Data analysis}

EMG activity was band-pass filtered between 0.15 and $1.0 \mathrm{kHz}$ and fed into a computer with a sampling rate of $10 \mathrm{kHz}$. These data were analyzed off-line. The maximum amplitude of the EMG signals during the time period of $t \pm 1 \mathrm{~ms}$ was calculated and designated the "EMG amplitude" at $t$. Then, the mean + SD of the EMG amplitude data for $300 \mathrm{~ms}$ before the CS onset in 100 trials was defined as the threshold, which was then used in the analysis below. In each trial, the average values for the EMG amplitude above threshold were calculated for a period of $300 \mathrm{~ms}$ before CS onset (pre-value), $30 \mathrm{~ms}$ after CS onset (startle-value), and $200 \mathrm{~ms}$ before the US onset (CR-value). When both the pre-value and startle-value were less than $10 \%$ of threshold, the trial was considered a valid trial. Among the valid trials, a trial was assumed to contain the $\mathrm{CR}$ if the $\mathrm{CR}$ value was larger than $1 \%$ of threshold and exceeded 2 times the pre-value. For the CS-alone trials, the period for CR-value calculation was extended to the presumptive US termination. The frequency of CRs in the valid trials (CR\%) was expressed as mean \pm s.e.m. To evaluate the effects on the startle eyeblink response to the tone CS, the number of trials whose startle value exceeded $10 \%$ of threshold during the acquisition session was computed and its ratio to the number of trials was calculated (after removal of those trials whose pre-value exceeded $10 \%$ of threshold). Statistical significance was determined by an ANOVA or $t$-test. $P<0.05$ was considered significant. 


\section{RESULTS}

\section{Effect of (+)MK-801 on acquisition of the conditioned response}

Using the noncompetitive NMDA receptor antagonist (+)MK-801, we investigated the role of NMDA receptors in 0-trace conditioning paradigm in GluR $\delta 2^{--}$mice. Our previous study revealed that these mutant mice require an intact hippocampus to acquire the eyeblink CR during 0-trace conditioning, while wild-type mice do not (Takatsuki et al., 2003). GluR $\delta 2^{--}$mice and wild-type mice received an intraperitoneal injection of (+)MK-801 (0.1 mg/kg) or saline $10 \mathrm{~min}$ before daily conditioning for 7 days. Figure 1A shows the CR\% for the saline-injected control group ( $\mathrm{n}=8)$ and the $(+)$ MK-801-injected group $(n=8)$ of wild-type mice. Both of them readily acquired the $\mathrm{CR}$. A two-way repeated-measures ANOVA revealed that the drug had no significant effect $\left(\mathrm{F}_{1,14}=2.35, P>0.1\right)$. In GluR $\delta 2^{--}$mice, the $\mathrm{CR} \%$ of the saline-injected control group $(\mathrm{n}=12)$ gradually increased to around $80 \%$ by the 7th day of conditioning (Fig. 1B). In contrast, the (+)MK-801-treated GluR $\delta 2^{--}$ mice $(n=12)$ exhibited a severe impairment in their acquisition of the $C R$. Their $C R \%$ reached only $30 \%$ after 7 days of conditioning. A two-way repeated-measures ANOVA confirmed a significant interaction between sessions and the drug $\left(\mathrm{F}_{6,132}=10.54, P<0.001\right)$. These results indicate that $(+) \mathrm{MK}-801$ at this dose greatly impairs learning during 0 -trace eyeblink conditioning in GluR $\delta 2^{--}$mice, but not in wild-type mice.

\section{Effect of (+)MK-801 on spontaneous eyeblink frequency and startle eyeblink frequency}

To confirm that the severe impairment of learning in GluR $\delta 2^{--}$mice was not due to deficits in basic sensory or motor performance, the effects on spontaneous eyeblink frequency measured during adaptation sessions and on startle eyeblink frequency to the tone CS assessed (Fig. 2). Statistical analysis using a two-way repeated-measures ANOVA indicated no significant differences in spontaneous eyeblink frequency between the saline-injected control group and the (+)MK-801-injected group in wild-type mice $\left(\mathrm{F}_{1,14}=4.12, P>0.05\right)$ and GluR $\delta 2^{--}$mice $\left(\mathrm{F}_{1,22}=2.12, P>0.1\right)$. The frequency of startle eyeblink to the tone $\mathrm{CS}$ during conditioning also did not differ significantly between control group and MK-801 group in wild-type mice ( $t$-test, $P>0.1)$ and GluR $\delta 2^{--}$mice $(t$-test, $P>0.1)$.

\section{Effect of (+)MK-801 on expression of the pre-acquired conditioned response}

Because the impairment in the mutant mice was so severe during the acquisition sessions, we also checked the possibility that expression of the CR might be being suppressed by the (+)MK-801 treatment during acquisition. Among the mice that received a saline injection during the 7 days of acquisition sessions with 0-trace conditioning (Fig. 1), we selected those mice whose average CR\% over the last three days of conditioning exceeded $60 \%$. All the wild-type mice $(\mathrm{n}=8)$ and 9 of $12 \mathrm{GluR} \delta 2^{--}$mice met this criterion, and they received three additional days of conditioning (the expression sessions) with (+)MK-801 injections $(0.1 \mathrm{mg} / \mathrm{kg}$, i.p.). When the injection solution was switched from saline to (+)MK-801, the CR\% of the GluR $\delta 2^{--}$mice decreased markedly, while that of the wild-type mice decreased only marginally (Fig. 3A). A paired $t$-test revealed a significant difference between the average $\mathrm{CR} \%$ over the last three days with saline injections and the $\mathrm{CR} \%$ on the first day with $(+) \mathrm{MK}-801$ injection both in GluR $\delta 2^{--}$mice $(P<0.001)$ and wild-type mice $(P<0.01)$. 
To further confirm the inhibition of CR expression by (+)MK-801, we looked at the recovery in CR expression after changing the injected solution from (+)MK-801 to saline. The mice that received injections of (+)MK-801 during the 7 days of acquisition sessions (8 wild-type mice and 12 GluR $\delta 2^{--}$mice used in the experiment shown in Fig. 1) received an additional three days of conditioning with saline injections. When the injection solution was switched from (+)MK-801 to saline, the CR\% of the GluR $\delta 2^{--}$mice rapidly increased, although the CR\% did not fully recover during these additional days of conditioning (Fig. 3B). In contrast, the $\mathrm{CR} \%$ of the wild-type mice showed almost no change on the first day. A paired $t$-test between the average CR\% over the last three days with an (+)MK-801 injection and the CR\% on the first day with a saline injection confirmed that there was a significant difference in GluR $\delta 2^{--}$mice $(P<0.05)$, whereas there were no significant differences in wild-type mice $(P>0.1)$. 


\section{DISCUSSION}

In the present study, we investigated the effect of the noncompetitive NMDA receptors antagonist (+)MK-801 on the learning ability of GluR $\delta 2^{--}$mice, which have a deficient cerebellar cortex, in '0-trace' eyeblink conditioning. We found that systemic application of (+)MK-801 (0.1 mg/kg, i.p.) severely impaired acquisition of the $\mathrm{CR}$ in GluR $\delta 2^{--}$mice, while it did not in wild-type mice. Expression of the pre-acquired CR was also markedly impaired in GluR $\delta 2^{--}$mice, whereas only a marginal impairment of CR expression was observed in wild-type mice. These results indicate that 0 -trace conditioning in GluR $\delta 2^{--}$mice depends largely on NMDA receptors both for acquisition and expression of the $\mathrm{CR}$.

NMDA receptors are extensively expressed over the forebrain, including the prefrontal cortex and the hippocampus (Watanabe et al., 1993), which play critical roles in acquisition during long-trace eyeblink conditioning (Solomon et al., 1986; Kronforst-Collins and Disterhoft, 1998; McLaughlin et al., 2002). In addition to these areas, NMDA receptors are also expressed in the cerebellum (Watanabe et al. 1994a) and brainstem (Watanabe et al. 1994b). Consistent with this, microinfusion of the competitive NMDA receptor antagonist APV into the deep cerebellar nuclei severely impairs acquisition during delay eyeblink conditioning in rabbits (Chen and Steinmetz, 2000), suggesting that some of the effect of (+)MK-801 might be attributable to its effect on the cerebellum. However, in the present study, acquisition was not significantly impaired during 0-trace conditioning in wild-type mice (Fig. 1A) and the impairment of CR expression was minimal (Fig. 3). These results suggest that the effect of (+)MK-801 on the role of the cerebellum and brainstem in mouse 0-trace conditioning must be relatively weak under the present condition.

In contrast to the small effect in wild-type mice, (+)MK-801 severely impaired acquisition in GluR $\delta 2^{--}$mice (Fig. 1). These results are consistent with our previous work that 0 -trace conditioning depends largely on the hippocampus in GluR $\delta 2^{--}$mice but not in wild-type mice (Takatsuki et al., 2003). Similar effects of (+)MK-801 have been observed in the hippocampus-dependent long-trace eyeblink conditioning in rabbits (Thompson and Disterhoft 1997) and mice (Takatsuki et al. 2001). Therefore, GluR $\delta 2^{--}$mice might learn 0 -trace eyeblink conditioning using a similar mechanism to that used in long-trace conditioning in wild-type animals. However, in addition to the severe impairment during acquisition sessions, (+)MK-801 also partially inhibited expression of the pre-acquired CR in GluR $\delta 2^{--}$mice (Fig. 3A). Thus, a part of the severe impairment in GluR $\delta 2^{--}$mice during acquisition sessions is attributable to inhibition of the CR expression. In contrast to the large effect in GluR $\delta 2^{--}$mice, (+)MK-801 had only a little effect on CR expression in wild-type mice (Fig. 3A). Similarly, CR expression in long-trace conditioning was not significantly inhibited by (+)MK-801 in wild-type mice, while its acquisition was severely impaired (Takatsuki et al. 2001). Therefore, (+)MK-801 differently affects 0 -trace conditioning in GluR $\delta 2^{--}$mice and long-trace conditioning in wild-type mice, though both heavily depend on the hippocampus for successful learning.

This impairment of CR expression by (+)MK-801 after sufficient learning was unexpected, because hippocampal lesions made after sufficient learning in 0-trace conditioning paradigm did not affect CR expression in GluR $\delta 2^{--}$mice, whereas a lesion made before the training did severely impair learning (Takatsuki et al., 2003). Therefore, the site of action of (+)MK-801 to inhibit the CR expression might be outside the 
hippocampus. At present, there are three candidates for this site. One is the cerebellum. Chen and Steinmetz (2000) have reported that some rabbits that were given APV injection to the deep cerebellar nuclei after sufficient learning showed impairment of CR expression, although most of the animals they examined did not show such impairment. Therefore, it is possible that GluR $\delta 2^{--}$mice, which have several deficiencies in the cerebellar cortex, preferentially use the expression mechanism that depends on the NMDA receptors in the cerebellar deep nuclei, while wild-type mice use an NMDA-independent mechanism for CR expression. The second candidate site is the medial prefrontal cortex, which plays an important role together with the hippocampus in the long-trace conditioning paradigm (Kronforst-Collins and Disterhoft, 1998; Weible et al., 2000; Takehara et al., 2003) and which also has an abundance of NMDA receptors (Watanabe et al., 1993). If GluR $\delta 2^{--}$mice depend much more than wild-type mice on the medial prefrontal cortex for CR expression after sufficient conditioning, then blockade of the NMDA receptors in this region might result in an impairment of CR expression. The medial prefrontal cortex plays a critical role when the hippocampus becomes inessential, which occurs one month after completion of long-trace conditioning in rats (Takehara et al., 2003). Therefore, it is plausible that the medial prefrontal cortex also plays an important role in GluR $\delta 2^{--}$mice, in which the hippocampus is no longer required after 7 days of conditioning (Takatsuki et al. 2003). Finally, the hippocampus cannot be excluded as a candidate, because it is possible that an abnormal hippocampus (caused by blockade of NMDA receptors in our study) could be much more detrimental than its absence (Solomon et al., 1983).

Impairment of CR expression by (+)MK-801 also has been reported in rabbits that received an intravenous injection of (+)MK-801 (Cox et al., 1994). The impairment of CR expression (as well as acquisition) in their study was much more profound than in other reports that adopted subcutaneous (Thompson and Disterhoft, 1997) or intraperitoneal (Takatsuki et al., 2001) injection of (+)MK-801, suggesting that the intravenous administration may have selectively affected an area that participates in CR expression and that is susceptible to blockade of NMDA receptors in rabbits. Therefore, it is likely that wild-type mice also have a mechanism for CR expression that largely depends on the normal functioning of NMDA receptors.

The present results suggest that GluR $\delta 2^{--}$mice may utilize an additional mechanism for expression of the CR and possibly for its acquisition as well to overcome the deficiencies in the cerebellar cortex. This mechanism may be present intrinsically but is not dominant in wild-type mice. Several characteristics of 0-trace conditioning in GluR $\delta 2^{--}$mice (such as the dependence on the hippocampus, muscarinic acetylcholine receptors and on NMDA receptors) are more similar to the features of long-trace conditioning than to those of delay conditioning in wild-type animals (Solomon et al., 1986; Kaneko and Thompson, 1997, Thompson and Disterhoft, 1997). Consistent with the effects of hippocampal lesion in various classical conditioning paradigms, the case of GluR $\delta 2^{--}$mice suggests that the forebrain may be more likely to be recruited if the task is more difficult for the cerebellum to perform because of deficiencies in the cerebellar cortex. Future study with microinfusion of APV into the cerebellum, the hippocampus and into the medial prefrontal cortex should provide more information about the mechanism underlying hippocampus-dependent eyeblink conditioning in GluR $\delta 2^{--}$mice and in wild-type mice as well. 


\section{Acknowledgements}

This work was supported by grants from the Ministry of Education, Culture, Sports, Science and Technology of Japan (\#16390015, \#17209002), from Core Research for Evolution Science and Technology of the Japan Science and Technology Agency, and from the Kato Memorial Bioscience Foundation. 


\section{References}

Aiba A, Kano M, Chen C, Stanton ME, Fox GD, Herrup K, Zwingman TA, Tonegawa S (1994) Deficient cerebellar long-term depression and impaired motor learning in mGluR1 mutant mice. Cell 79:377-388.

Araki K, Meguro H, Kushiya E, Takayama C, Inoue Y, Mishina M (1993) Selective expression of the glutamate receptor channel $\delta 2$ subunit in cerebellar Purkinje cells. Biochem Biophys Res Commun 197:1267-1276.

Berger TW, Orr WB (1983) Hippocampectomy selectively disrupts discrimination reversal conditioning of the rabbit nictitating membrane response. Behav Brain Res 8:49-68.

Chen G, Steinmetz JE (2000) Intra-cerebellar infusion of NMDA receptor antagonist AP5 disrupts classical eyeblink conditioning in rabbits. Brain Res 887:144-156.

Chen L, Bao S, Lockard JM, Kim JJ, Thompson RF (1996) Impaired classical eyeblink conditioning in cerebellar-lesioned and Purkinje cell degeneration ( $p c d$ ) mutant mice. J. Neurosci 16:2829-2838.

Cox J, Guthrie R, Macrae M, Kehoe EJ (1994) MK801 impairs acquisition and expression of conditioned responses in the rabbit nictitating membrane preparation. Psychobiol 22:156-166.

Funabiki K, Mishina M, Hirano T (1995) Retarded vestibular compensation in mutant mice deficient in $\delta 2$ glutamate receptor subunit. Neuroreport 7:189-192.

Ito M (1989) Long-term depression. Ann Rev Neurosci 12:85-102.

Kashiwabuchi N, Ikeda K, Araki K, Hirano T, Shibuki K, Takayama C, Inoue Y, Kutsuwada T, Yagi T, Kang Y, Aizawa S, Mishina M (1995) Impairment of motor coordination, Purkinje cell synapse formation, and cerebellar long-term depression in GluR $\delta 2$ mutant mice. Cell 81:245-252.

Kaneko T, Thompson RF (1997) Disruption of trace conditioning of the nictitating membrane response in rabbits by central cholinergic blockade. Psychopharmacol 131:161-166.

Kishimoto Y, Hirono M, Sugiyama T, Kawahara S, Nakao K, Kishio M, Katsuki M, Yoshioka T, Kirino Y (2001a) Impaired delay but normal trace eyeblink conditioning in PLC $\beta 4$ mutant mice. Neuroreport 12:2919-2922.

Kishimoto Y, Kawahara S, Fujimichi R, Mori H, Mishina M, Kirino Y (2001b) Impairment of eyeblink conditioning in GluR $\delta 2^{--}$mice depends on the temporal overlap between conditioned and unconditioned stimuli. Eur J Neurosci 14:1515-1521.

Kishimoto Y, Kawahara S, Kirino Y, Kadotani H, Nakamura Y, Ikeda M, Yoshioka T (1997) Conditioned eyeblink response is impaired in mutant mice lacking NMDA receptor subunit NR2A. Neuroreport 8:3717-3721

Kishimoto Y, Kawahara S, Mori H, Mishina M, Kirino Y (2001c) Long-trace interval eyeblink conditioning is impaired in mutant mice lacking the NMDA receptor subunit $\varepsilon 1$. Eur J Neurosci 13:1221-1227.

Kishimoto Y, Kawahara S, Suzuki M, Mori H, Mishina M, Kirino Y (2001d) Classical eyeblink conditioning in glutamate receptor subunit $\delta 2$ mutant mice is impaired in the delay paradigm but not in the trace paradigm. Eur J Neurosci 13:1249-1253.

Koekkoek SK, Hulscher HC, Dortland BR, Hensbroek RA, Elgersma Y, Ruigrok TJ, De Zeeuw CI (2003) 
Cerebellar LTD and learning-dependent timing of conditioned eyelid responses. Science 301:1736-1739.

Kronforst-Collins MA, Disterhoft JF (1998) Lesions of the caudal area of rabbit medial prefrontal cortex impair trace eyeblink conditioning. Neurobiol Learn Mem 69:147-162.

Kurihara H, Hashimoto K, Kano M, Takayama C, Sakimura K, Mishina M, Inoue Y, Watanabe M (1997) Impaired parallel fiber->Purkinje cell synapse stabilization during cerebellar development of mutant mice lacking the glutamate receptor $\delta 2$ subunit. J Neurosci 17:9613-9623.

Landsend AS, Amiry-Moghaddam M, Matsubara A, Bergersen L, Usami S, Wenthold RJ, Ottersen OP (1997) Differential localization of $\delta$ glutamate receptors in the rat cerebellum: coexpression with AMPA receptors in parallel fiber-spine synapses and absence from climbing fiber-spine synapses. J Neurosci 17:834-842.

Lomeli H, Sprengel R, Laurie DJ, Köhr G, Herb A, Seeburg PH, Wisden W (1993) The rat delta-1 and delta-2 subunits extend the excitatory amino acid receptor family. FEBS Lett 315:318 -322.

McCormick DA, Clark G.A, Lavond DG, Thompson RF (1982) Initial localization of the memory trace for a basic form of learning. Proc Natl Acad Sci USA 79:2731-2735.

McLaughlin J, Skaggs H, Churchwell J, Powell DA (2002) Medial prefrontal cortex and Pavlovian conditioning: trace versus delay conditioning. Behav Neurosci 116:37-47.

Miyata M, Kim HT, Hashimoto K, Lee TK, Cho SY, Jiang H, Wu Y, Jun K, Wu D, Kano M, Shin HS (2001) Deficient long-term synaptic depression in the rostral cerebellum correlated with impaired motor learning in phospholipase C $\beta 4$ mutant mice. Eur J Neurosci 13:1945-1954.

Moyer JR Jr, Deyo RA, Disterhoft JF (1990) Hippocampectomy disrupts trace eye-blink conditioning in rabbits. Behav Neurosci 104:243-252.

Prokasy WF, Kesner RP, Calder LD (1983) Posttrial electrical stimulation of the dorsal hippocampus facilitates acquisition of the nictitating membrane response. Behav Neurosci 97:890-896.

Sakamoto T, Takatsuki K, Kawahara S, Kirino Y, Niki H, Mishina M (2005) Role of hippocampal NMDA receptors in trace eyeblink conditioning. Brain Res 1039:130-136.

Salafia WR, Chiaia NL, Ramirez JJ (1979) Retardation of rabbit nictitating membrane conditioning by subseizure electrical stimulation of hippocampus. Physiol Behav 22:451-455.

Shibuki K, Gomi H, Chen L, Bao S, Kim JJ, Wakatsuki H, Fujisaki T, Fujimoto K, Katoh A, Ikeda T, Chen C, Thompson RF, Itohara S (1996) Deficient cerebellar long-term depression, impaired eyeblink conditioning, and normal motor coordination in GFAP mutant mice. Neuron 16:587-599.

Solomon PR, Solomon SD, Schaaf EV, Perry HE (1983) Altered activity in the hippocampus is more detrimental to classical conditioning than removing the structure. Science 220:329-331.

Solomon PR, Vander Schaaf ER, Thompson RF, Weiss DJ (1986) Hippocampus and trace conditioning of the rabbit's classically conditioned nictitating membrane response. Behav Neurosci 100:729-744.

Takatsuki K, Kawahara S, Kotani S, Fukunaga S, Mori H, Mishina M, Kirino Y (2003) The hippocampus plays an important role in eyeblink conditioning with a short trace interval in glutamate receptor subunit $\delta 2$ mutant mice. J Neurosci 23:17-22.

Takatsuki K, Kawahara S, Mori H, Mishina M, Kirino Y (2002) Scopolamine impairs eyeblink conditioning in 
cerebellar LTD-deficient mice. Neuroreport 13:159-162.

Takatsuki K, Kawahara S, Takehara K, Kishimoto Y, Kirino Y (2001) Effects of the noncompetitive NMDA receptor antagonist MK-801 on classical eyeblink conditioning in mice. Neuropharmacol 41:618-628.

Takayama C, Nakagawa S, Watanabe M, Mishina M, Inoue Y (1996) Developmental changes in expression and distribution of the glutamate receptor channel $\delta 2$ subunit according to the Purkinje cell maturation. Brain Res Dev Brain Res 92:147-155.

Takehara K, Kawahara S, Kirino Y (2003) Time-dependent reorganization of the brain components underlying memory retention in trace eyeblink conditioning. J Neurosci 23:9897-9905.

Takehara K, Kawahara S, Takatsuki K, Kirino Y (2002) Time-limited role of the hippocampus in the memory for trace eyeblink conditioning in mice. Brain Res 951:183-190.

Thompson LT, Disterhoft JF (1997) N-methyl-D-aspartate receptors in associative eyeblink conditioning: both MK-801 and phencyclidine produce task- and dose-dependent impairments. J Pharmacol Exp Ther 281:928-940.

Thompson RF, Bao S, Chen L, Cipriano BD, Grethe JS, Kim JJ, Thompson JK, Tracy JA, Weninger MS, Krupa DJ (1997) Associative learning. Int Rev Neurobiol 41:151-189.

Thompson RF, Krupa DJ (1994) Organization of memory traces in the mammalian brain. Ann Rev Neurosci 17:519-549.

Tseng W, Guan R, Disterhoft JF, Weiss C (2004) Trace eyeblink conditioning is hippocampally dependent in mice. Hippocampus 14:58-65.

Watanabe M, Inoue Y, Sakimura K, Mishina M (1993) Distinct distributions of five $N$-methyl-D-aspartate receptor channel subunit mRNAs in the forebrain. J Comp Neurol 338:377-390.

Watanabe M, Mishina M, Inoue Y (1994a) Distinct spatiotemporal expressions of five NMDA receptor channel subunit mRNAs in the cerebellum. J Comp Neurol 343:513-519.

Watanabe M, Mishina M, Inoue Y (1994b) Distinct spatiotemporal expressions of five NMDA receptor channel subunit mRNAs in the brainstem. J Comp Neurol 343:520-531.

Weible AP, McEchron MD, Disterhoft JF (2000) Cortical involvement in acquisition and extinction of trace eyeblink conditioning. Behav Neurosci 114:1058-1067.

Weiss C, Bouwmeester H, Power JM, Disterhoft JF (1999) Hippocampal lesions prevent trace eyeblink conditioning in the freely moving rat. Behav Brain Res 99:123-132.

Yoshida T, Katoh A, Ohtsuki G Mishina M, Hirano T (2004) Oscillating Purkinje neuron activity causing involuntary eye movement in a mutant mouse deficient in the glutamate receptor $\delta 2$ subunit. J Neurosci 24:2440-2448. 


\section{Figure legends}

Fig. 1. Effects of (+)MK-801 on acquisition of the CR during 7 days of 0-trace conditioning in wild-type mice (A) and GluR $\delta 2^{--}$mice (B). Saline or (+)MK-801 $(0.1 \mathrm{mg} / \mathrm{kg}$ ) was intraperitoneally injected $10 \mathrm{~min}$ before daily conditioning in wild-type mice ( $\mathrm{n}=8$ for saline and MK-801 group each) and GluR $\delta 2^{--}$mice ( $\mathrm{n}=12$ for each group). The error bar indicates the standard error of the mean.

Fig. 2. Effects of (+)MK-801 on the spontaneous eyeblink and the startle eyeblink to the tone CS. (A) Effect on spontaneous eyeblink frequency during adaptation sessions, which were performed before the 7-day acquisition sessions. Eyeblink frequency was recorded using the same protocol as that used for the acquisition sessions except that no stimuli were presented. On the first day (sp1), spontaneous eyeblink frequency was recorded without drug injection. On the second day (sp2), saline or $(+) \mathrm{MK}-801(0.1 \mathrm{mg} / \mathrm{kg})$ was intraperitoneally injected 10 min before the adaptation session. (B) Effect on startle eyeblink frequency to the tone CS during conditioning. The data were collected from 7 days of conditioning. The error bar indicates the standard error of the mean.

Fig. 3. Effects of (+)MK-801 on expression of the CR. After 7 days of conditioning (shown in Fig.1), the injection solution was switched from saline to (+)MK-801 (A) or from (+)MK-801 to saline (B). The data during the last three days of conditioning (5-7th days of conditioning) and the subsequent three days of expression sessions (exp1-3) are shown. (A) Inhibitory effect on expression of the pre-acquired CR. The wild-type mice ( $\mathrm{n}=8)$ and the GluR $\delta 2^{-\leftarrow}$ mice $(\mathrm{n}=9)$, whose average CR\% over the last three days with saline injection had exceeded $60 \%$, received additional three days of conditioning with (+)MK-801 injection. (B) Recovery from inhibition by (+)MK-801. The wild-type mice $(n=8)$ and the GluR $\delta 2^{--}$mice $(n=12)$, which were conditioned with (+)MK-801 injection for 7 days, received additional three days of conditioning with saline injection. Empty and filled symbols indicate saline and (+)MK-801 injection groups, respectively. The error bar indicates the standard error of the mean. 
Fig. 1
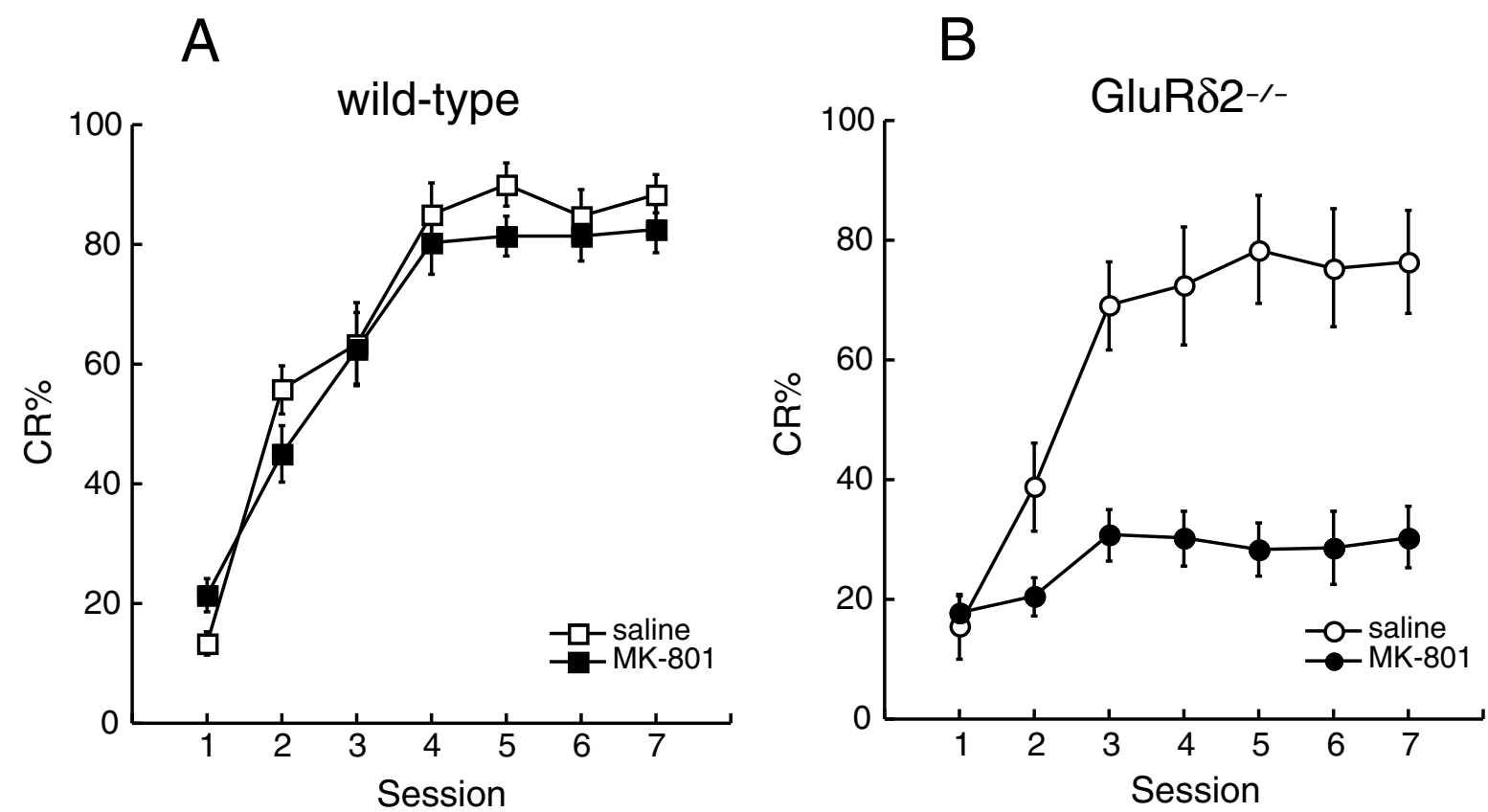
Fig. 2
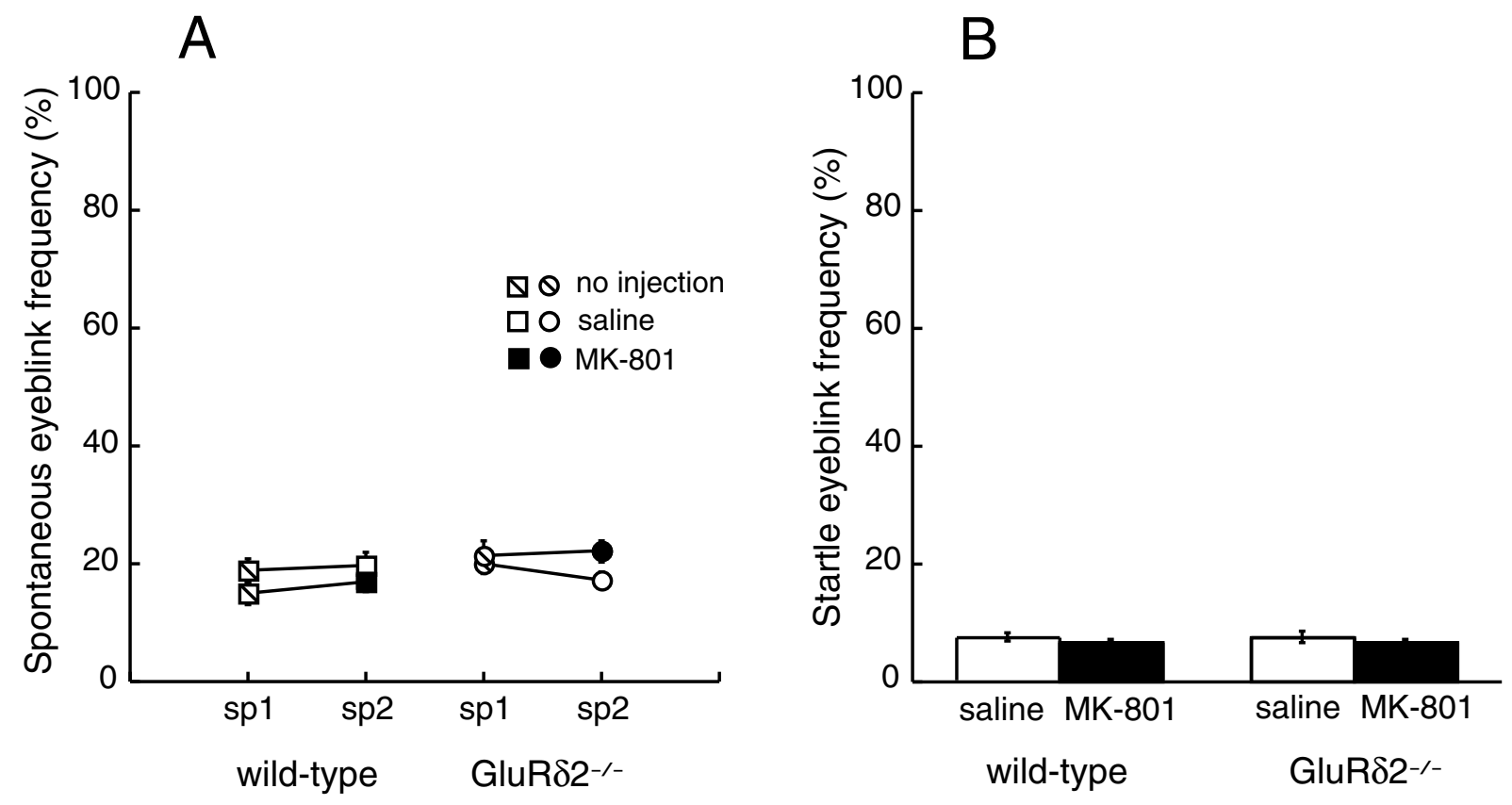
Fig. 3
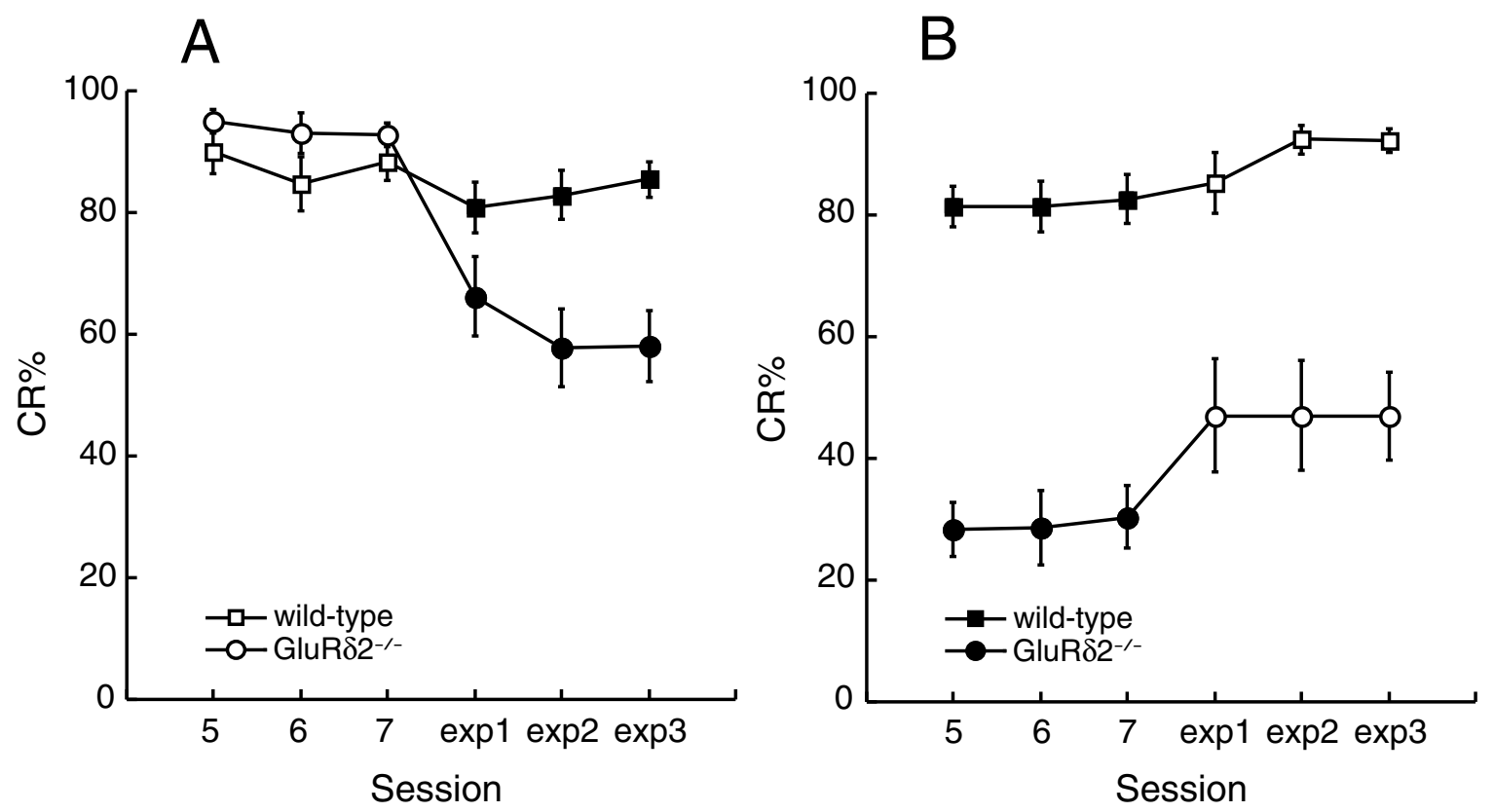